\title{
Imaging Membrane Curvature inside a FceRI-Centric Synapse in RBL-2H3 Cells Using TIRF Microscopy with Polarized Excitation
}

\author{
Rosa Machado ${ }^{1}$, Justin Bendesky ${ }^{1}$, Madison Brown ${ }^{1,2}$, Kathrin Spendier ${ }^{1,2, *(\mathbb{C} \text { and }}$ \\ Guy M. Hagen ${ }^{1, *}$ \\ 1 UCCS Center for the Biofrontiers Institute, University of Colorado at Colorado Springs, Colorado Springs, \\ CO 80918, USA \\ 2 Department of Physics and Energy Science, University of Colorado at Colorado Springs, Colorado Springs, \\ CO 80918, USA \\ * Correspondence: kspendie@uccs.edu (K.S.); ghagen@uccs.edu (G.M.H.)
}

Received: 15 April 2019; Accepted: 28 June 2019; Published: 4 July 2019

\begin{abstract}
Total internal reflection fluorescence microscopy with polarized excitation (P-TIRF) can be used to image nanoscale curvature phenomena in live cells. We used P-TIRF to visualize rat basophilic leukemia cells (RBL-2H3 cells) primed with fluorescent anti-dinitrophenyl (anti-DNP) immunoglobulin E (IgE) coming into contact with a supported lipid bilayer containing mobile, monovalent DNP, modeling an immunological synapse. The spatial relationship of the IgE-bound high affinity IgE receptor ( $F c \varepsilon R I)$ to the ratio image of P-polarized excitation and S-polarized excitation was analyzed. These studies help correlate the dynamics of cell surface molecules with the mechanical properties of the plasma membrane during synapse formation.
\end{abstract}

Keywords: total internal reflection fluorescence microscopy; P-TIRF; rat basophilic leukemia cells; RBL-2H3; IgE receptor; FceRI; plasma membrane; supported lipid bilayer

\section{Introduction}

The ability of eukaryotic cells to communicate with each other is important for numerous biological processes, including cell growth, motility, and immune function. This communication can occur through soluble factors (cytokines, interleukins, etc.), or by physical cell-cell contact. In the latter case, the immunological synapse is one of the most important communication strategies in immune cells. These intimate cell-cell contacts result in intracellular signaling and are accompanied by large-scale spatial reorganization of membrane proteins within the cell-cell junction. For example, the ability to form a synapse is a well-known communication strategy between $\mathrm{T}$ cells and antigen-presenting cells such as B cells [1,2]. A recent study has shown that mast cells can form a synapse with dendritic cells, and that this can facilitate antigen transfer in T cell activation processes [3]. Additionally, mast cells can engage $\gamma \delta$ T cells to protect against viral infections by forming mast cell- $\gamma \delta \mathrm{T}$ cell conjugates. In this cell-cell conjugate CD3 and $\gamma \delta$ T-cell receptors are strongly polarized toward the mast cell contact site resulting in an immunological synapse formation [4]. These findings suggests that mast cells, and possibly basophils, can serve as nonconventional antigen-presenting cells and may play a larger role in signaling between physically contacting cells.

To study immunological synapse formation we used total internal reflection fluorescence (TIRF) microscopy of fluorescently labeled cells interfacing with a supported lipid bilayer (SLB) containing an appropriate ligand [5]. We have previously demonstrated that rat basophilic leukemia (RBL-2H3) cells possess the machinery to form a FCERI-centric synapse in response to antigen-containing SLBs [5-7]. RBL-2H3 cells are derived from rat basophils, but are commonly used in studies of allergic responses 
which are typically associated with mast cells [8,9]. Similar to mast cells, widely used RBL-2H3 cells degranulate in response to multivalent antigens which crosslink immunoglobulin $\mathrm{E}$ (IgE) when bound to its high affinity receptor, FceRI [9,10]. RBL-2H3 cells can be weakly activated when in contact with fluid lipid bilayers containing monovalent ligands such as dinitrophenol (DNP) [5,11]. In this model system IgE-FceRI are not cross-linked but aggregate at cell surface protrusions that form the initial contact points with the substrate [7]. After initial IgE-FceRI cluster formation, small receptor clusters coalesce to form a large central patch, termed the mast cell synapse [5,7]. During activation RBL-2H3 cells are known to change their morphology, with the cell becoming more ruffled [12]. However, a detailed picture of how the transformation of cell membrane shape affects the organization of receptors is still lacking.

Recent studies, for example those summarized in Reference [13], have focused on identifying proteins that are involved in membrane curvature generation and sensing. In these investigations a surprising abundance of proteins that couple membrane shape to cellular membrane function have been discovered. In this context, we have previously shown that an elevated concentration of curvature-inducing peptides can interfere with the formation of a mast cell synapse in RBL-2H3 cells [14], and it is known that receptor activity at the plasma membrane can be enhanced by membrane curvature changes [15]. To investigate the role of the plasma membrane environment in the formation of FceRI-centric synapses in RBL-2H3 cells, we wish to relate the spatial and temporal dynamics of the IgE receptor, FceRI, with what may be very small changes in cell membrane topography. This can be accomplished using polarized-excitation TIRF microscopy (P-TIRF) [16-25].

We used P-TIRF to determine the relative molecular orientation of the fluorescent lipophilic tracer DiI- $\mathrm{C}_{16}$ in RBL-2H3 cells which were labeled with fluorescent IgE. DiI- $\mathrm{C}_{16}$ inserts into the plasma membrane of cells in a specific orientation such that the chromophore is always oriented parallel to the membrane. The dye is preferentially excited by linearly polarized light according to its orientation. DiI- $\mathrm{C}_{16}$ molecules in areas of the membrane with high curvature in the axial direction are preferentially excited by P-polarized excitation [22]. In a microscope, P-polarized light can be achieved using through-the-objective type TIRF illumination with high NA objective lenses [22], and a ratio of P-polarized excitation and S-polarized excitation images (P/S ratio) can be used to assess dye orientation and thereby axial membrane curvature [20].

In this study we used P-TIRF to image live RBL-2H3 cells in which we labeled the membrane receptor FceRI with fluorescent $\operatorname{IgE}$ (IgE-488) and labeled the plasma membrane with DiI- $\mathrm{C}_{16}$. We then allowed the cells to settle on and engage supported lipid bilayers containing mobile lipids bearing the IgE ligand DNP. This allows us to correlate receptor patch formation and dynamics with measurements of membrane curvature, while also exploiting the optical sectioning property of TIRF microscopy. We used an innovative optical design and sensitive SCMOS and EMCCD detectors to capture high signal to noise ratio images, which we used to generate P-TIRF ratio images that indicate membrane curvature. These are the first experiments which combine imaging of membrane curvature phenomena with simultaneous imaging of the formation of a model immunological synapse that we are aware of. Specifically, we analyzed the spatial relationship of regions containing or lacking IgE-bound FceRI to the corresponding $\mathrm{P} / \mathrm{S}$ ratio image by plotting normalized histograms of the number of pixels with particular $\mathrm{P} / \mathrm{S}$ ratios in the aforementioned FceRI regions. Membrane regions containing IgE-bound FCERI consistently had lower P/S ratios than those regions lacking the receptor, though this varied considerably from cell to cell.

\section{Materials and Methods}

\subsection{Samples}

RBL-2H3 cells, obtained from ATCC (Manassas, VA, USA), were maintained in DMEM supplemented with $10 \%$ FCS, $100 \mathrm{U} / \mathrm{mL}$ penicillin, and $100 \mathrm{U} / \mathrm{mL}$ streptomycin (all from Invitrogen) at 
$37^{\circ} \mathrm{C}, 5 \% \mathrm{CO}_{2}$, and $100 \%$ humidity. Cells were grown in tissue culture flasks, and were transferred to suspension culture petri dishes $24-48$ hours before imaging.

We labeled anti-dinitrophenol IgE (anti-DNP-IgE, clone SPE-7, Sigma-Aldrich, D8406) with DyLight 488 NHS ester (Thermo Fisher Scientific, 46403) according to the manufacturer's protocols (IgE-488). After size-exclusion chromatography, the final dye to protein ratio was typically 5-6 dye molecules per protein molecule as measured with a Nanodrop spectrophotometer (Thermo Fisher Scientific). Cells in suspension culture dishes were labeled with $0.5 \mathrm{~nm}$ fluorescent IgE for typically $12-20 \mathrm{~h}$ before imaging.

To label the plasma membrane for P-TIRF measurements, we labeled the cells with $1 \mu \mathrm{M}$ DiI- $\mathrm{C}_{16}$ (Thermo Fisher Scientific, D384). To prepare the DiI- $\mathrm{C}_{16}$ we dissolved the solid material in ethanol at a concentration of $100 \mathrm{~mm}$, then diluted it to $1 \mu \mathrm{M}$ in PBS. After $5-10 \mathrm{~min}$ incubation at $37^{\circ} \mathrm{C}$, we washed the cells with fresh PBS.

We formed liposomes containing 75\% 1-palmitoyl-2-oleoyl-sn-glycero-3-phosphocholine (POPC) and 25\% 1,2-dihexadecanoyl-sn-glycero-3-phosphoethanolamine-N-[6-[(2,4-dinitrophenyl)amino]caproyl] (DNP-CAP-PE, Avanti Polar Lipids) by mixing the two components dissolved in chloroform, then evaporating the solvent with a blow-down of compressed air. We then dissolved the mixture in PBS and sonicated it on ice for 10 minutes using a probe type sonicator (Branson Sonifier 450), until the liposome mixture appeared clear.

To prepare supported lipid bilayers, we pipetted $50 \mu \mathrm{L}$ of liposome mixture on to a clean petri dish at $37^{\circ} \mathrm{C}$, then overlaid the droplet with a $25 \mathrm{~mm} \# 1.5$ coverslip that had been cleaned in piranha solution ( $30 \% \mathrm{H}_{2} \mathrm{O}_{2}$ in concentrated $\left.\mathrm{H}_{2} \mathrm{SO}_{4}\right)$ [26]. After 15 min we immersed the petri dish and coverslip in distilled water, then inverted the coverslip and placed it in a microscope imaging chamber (RC-40LP, Warner Instruments). This prevented the bilayer from coming into contact with air.

\subsection{Microscope Setup and Acquisition}

Our setup is based on a DMI300B or DMI8 microscope with an oil immersion HCX PL APO $100 \times / 1.47$ NA TIRF objective (Leica, Manheim, Germany). We used an Evolve 512 EMCCD camera (Photometrics, Tucson, Arizona) and micromanager software [27] or a Zyla 4.2+ sCMOS camera with IQ software (Andor, Belfast, Northern Ireland). The TIRF module (custom designed by Spectral Applied Research, Ontario, Canada) uses a liquid crystal polarization rotator and controller (Meadowlark Optics, Frederick, CO, USA). The controller is signaled to switch polarizations using an Arduino under the control of micromanager software [28]. The time required to switch polarization states is less than $10 \mathrm{~ms}$, allowing us to record pairs of images with P-polarized and S-polarized excitation with very little delay between the images, and with no moving parts.

Sample fluorescence was isolated with a DV2 image splitter (Photometrics) or with a Lambda 10-B filter wheel (Sutter Instrument, Novato, CA, USA) and emission filters appropriate for IgE-488 and DiI-C ${ }_{16}$ (ET series, Chroma, Bellows Falls, Vermont). For live cell experiments with SLBs, we warmed the objective to $37^{\circ} \mathrm{C}$ using an objective heater (Bioptechs). In some experiments we used a custom-made microscope incubation chamber. A diagram and photograph of the microscope setup are shown in Figure 1. 

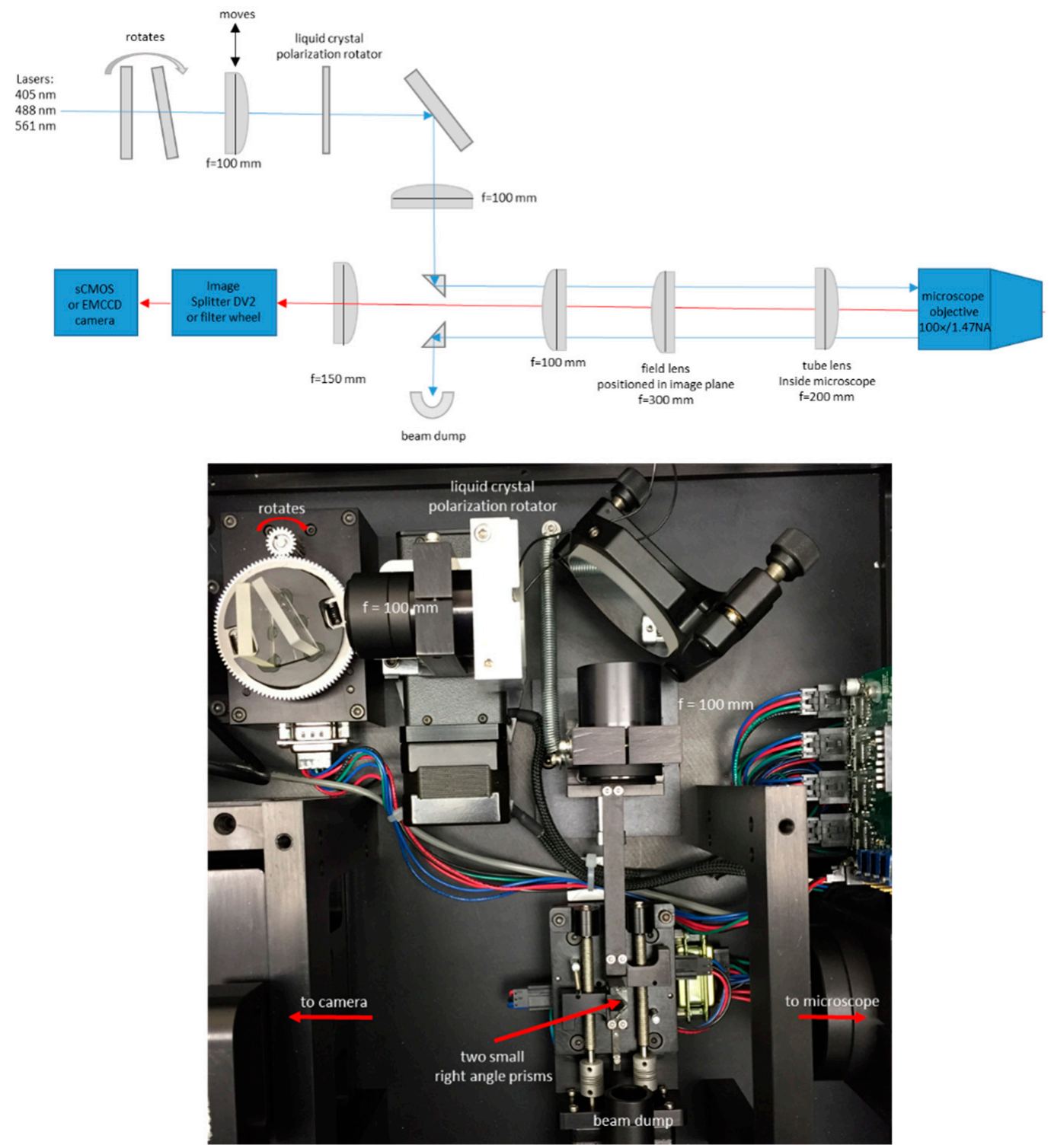

Figure 1. Setup of total internal reflection fluorescence microscope with polarized excitation. Diagram and photograph. Diagram not to scale. Use of small ( 2 $\mathrm{mm})$ right-angle prisms [29] to steer the laser beam removes the need for dichroic mirrors. The moving lens and prisms are stepper-motor actuated under computer control and allow precise adjustment of the beam position, and thus of the penetration depth of the evanescent field.

This setup uses a small right-angle prism (legs $\sim 2 \mathrm{~mm}$ ) to steer the laser beam into the back aperture of the objective [29]. A second small right-angle prism steers the reflected beam into a beam dump. This approach eliminates the need for a dichroic mirror. The two prisms, and also one lens, are mounted on stepper-motor actuated stages under computer control. This allows precise and reproducible positioning of the laser beam in the objective back aperture, thereby allowing us to achieve the desired incidence angle (TIRF angle), and therefore the desired penetration depth of the evanescent field. A rotating plate is also stepper-motor actuated under computer control and is used for wavelength compensation such that different illumination wavelengths can have the same evanescent field penetration depth. In this setup the azimuthal position of the beam in the back aperture is fixed. This can result in uneven illumination and interference fringes in the image, but this problem was not severe in our case. Spinning the laser beam around the periphery of the back aperture within a single camera exposure can help eliminate such interference patterns [30]. 


\subsection{Membrane Curvature Visualization}

A detailed theoretical discussion of the workings of P-TIRF can be found in Reference [17]. Briefly, a polarization component of light along the optical axis or the $\mathrm{z}$-axis of the microscope is unique to TIRF microscopy. With epi-illumination, the electromagnetic field propagates along the optical axis and only has components in the $x-y$ plane with respect to the sample. With TIRF illumination, P-polarization results in polarized illumination along the $x$-axis and the $z$-axis, with the $x$-component being about $5 \%$ of the z-component. S-polarization results in polarized illumination only along the y-axis. The probability of a fluorophore to absorb a photon is calculated by the dot product of the fluorophore's excitation dipole and the polarization of the absorbed light. Therefore, for fluorophores in which the chromophore is oriented in a specific way, one can determine the orientation of the fluorophore by switching between P-polarized and S-polarized TIRF excitation.

The emission light intensities $\mathrm{P}$ and $\mathrm{S}$ gathered by an objective from P-polarized and S-polarized excitation are [22]

$$
\begin{gathered}
P=2 \pi \int C \eta(\theta) \cos ^{2} \theta \sin \theta \mathrm{d} \theta, \\
S=\pi \int C \eta(\theta)\left(1-\cos ^{2} \theta\right) \sin \theta \mathrm{d} \theta,
\end{gathered}
$$

where $C=P+2 S$ is the local concentration of fluorophores, and $\eta(\theta)$ is a factor that describes the orientational distribution of the detected fluorophores. DiI- $\mathrm{C}_{16}$ molecules insert in the membrane with their excitation dipoles parallel to the plane of the membrane [16]. DiI- $\mathrm{C}_{16}$ molecules that are located in areas of the membrane with high axial curvature are excited preferentially by P-polarized excitation in TIRF and a simple ratio $\mathrm{R}$ (or ratio image)

$$
\mathrm{R}=\mathrm{P} / \mathrm{S}
$$

can be calculated to indicate the local orientation of the cell membrane.

To determine if the excitation intensities are the same for both polarizations, we collected signals (using P- or S-polarized epi-illumination) from DiI- $\mathrm{C}_{16}$ in solution for both polarizations. We found that this ratio for polarized excitation was close to 1.0. Therefore, to calculate the ratio we simply divided the $\mathrm{P}$ and $\mathrm{S}$ images without any additional processing. In some cases, we averaged multiple ratio images to reduce noise.

\section{Results}

\subsection{Membrane Curvature Can Be Detected Using P-TIRF and the Dye DiI- $C_{16}$}

We grew RBL-2H3 cells on coverslips overnight, then labeled them with $1 \mu \mathrm{M}$ DiI- $\mathrm{C}_{16}$. After washing the cells three times with PBS, we imaged them using P-TIRF in PBS or in media in an open-top chamber. We typically recorded 1-40 images in each orientation of polarized excitation, switching the polarization between each acquired image. An example of the results is shown in Figure 2 . In this example, large differences are apparent between the two excitation polarizations. Figure 2a,b are shown with the same brightness and contrast settings, while Figure $2 \mathrm{c}$ shows a two-color overlay to emphasize the differences. Figure $2 \mathrm{~d}$ shows an average of 10 ratio images, with the brightness adjusted to a scale ranging from ratios of $0-3$. We measured the $\mathrm{P} / \mathrm{S}$ ratio, Equation (3), in two regions of interest (indicated in Figure 2d). We found that the ratio was $1.822 \pm 0.295$ (mean \pm standard deviation) in region 1 (high curvature area), and $0.694 \pm 0.0661$ in region 2 (low curvature, flat area). When creating two-color overlay or ratio images, we measured the lateral shift between the two images using the 'find shift' routine within DIPImage [31], an image processing toolbox for MATLAB (The Mathworks, Natick, MA, USA). We found that the shift between the two images was less than about 0.3 pixels in both $X$ and $Y$. In our case this corresponds to less than $15 \mathrm{~nm}$ and so we did not perform an image registration procedure. 

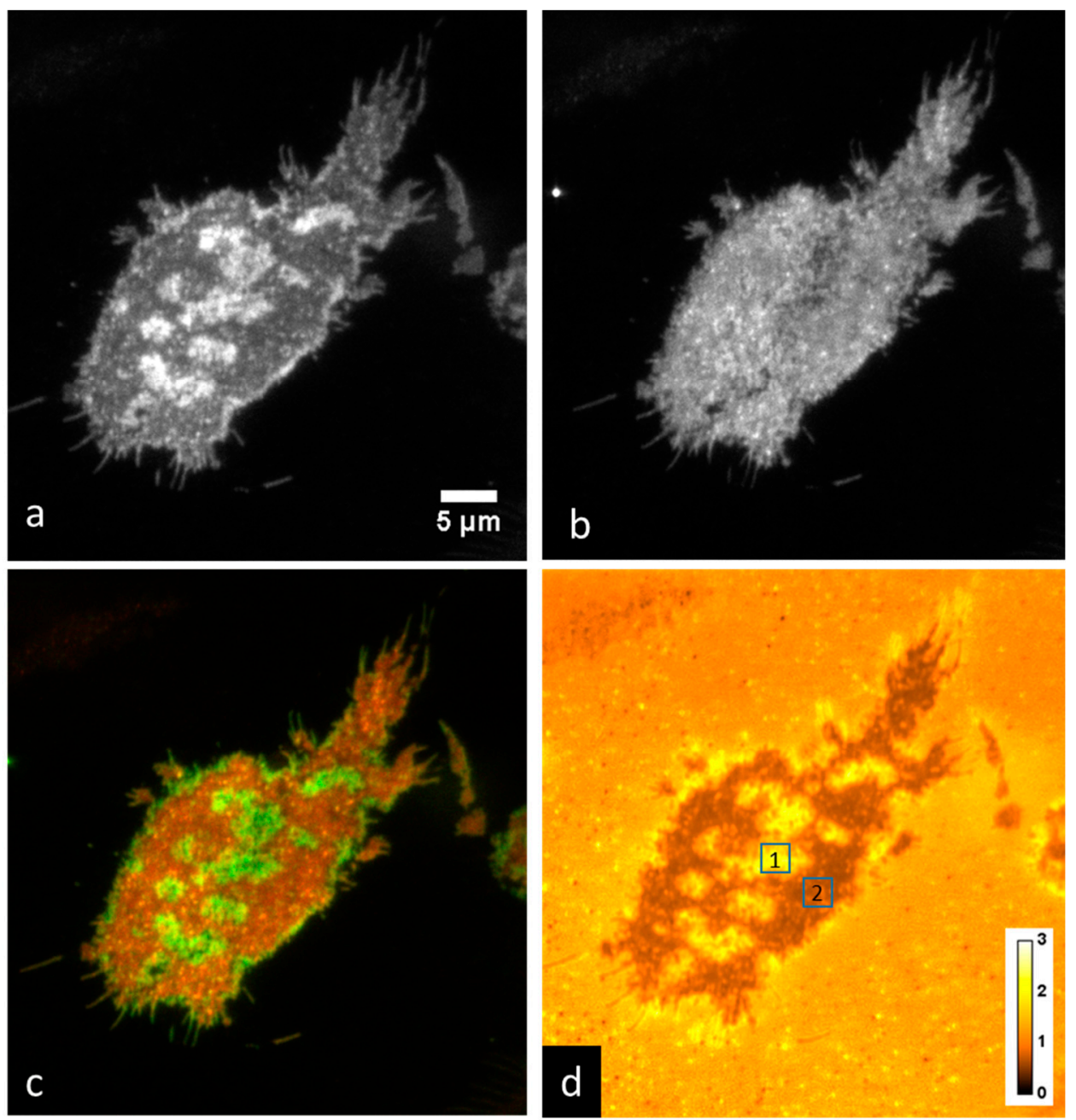

Figure 2. Imaging membrane curvature with DiI- $\mathrm{C}_{16}$ in RBL-2H3 cells grown on a coverslip acquired with an Evolve 512 EMCCD camera. Shown are (a) P-polarized excitation, (b) S-polarized excitation, (c) red-green two-color overlay of P-polarized excitation and S-polarized excitation, (d) average of ten P-polarized excitation and S-polarized excitation ratio $(\mathrm{P} / \mathrm{S})$ images. Region of interest $(\mathrm{ROI}) 1: \mathrm{P} / \mathrm{S}=$ $1.822 \pm 0.295 ;$ ROI $2: \mathrm{P} / \mathrm{S}=0.694 \pm 0.0661$.

Axial membrane curvature is high in filopodia, which are approximately cylindrical and thus have a high aspect ratio [24]. We imaged membrane curvature using DiI- $\mathrm{C}_{16}$ labeled RBL-2H3 cells grown on a coverslip, acquired with the Zyla 4.2+ sCMOS camera. Figure 3a shows an average of $40 \mathrm{P} / \mathrm{S}$ ratio images, while Figure $3 \mathrm{~b}$ shows a zoomed-in view of the region of interest indicated in Figure $3 \mathrm{a}$. We measured the $\mathrm{P} / \mathrm{S}$ ratio from top to bottom along the line indicated in Figure $3 \mathrm{~b}$ and plotted the results in the inset in the figure. 

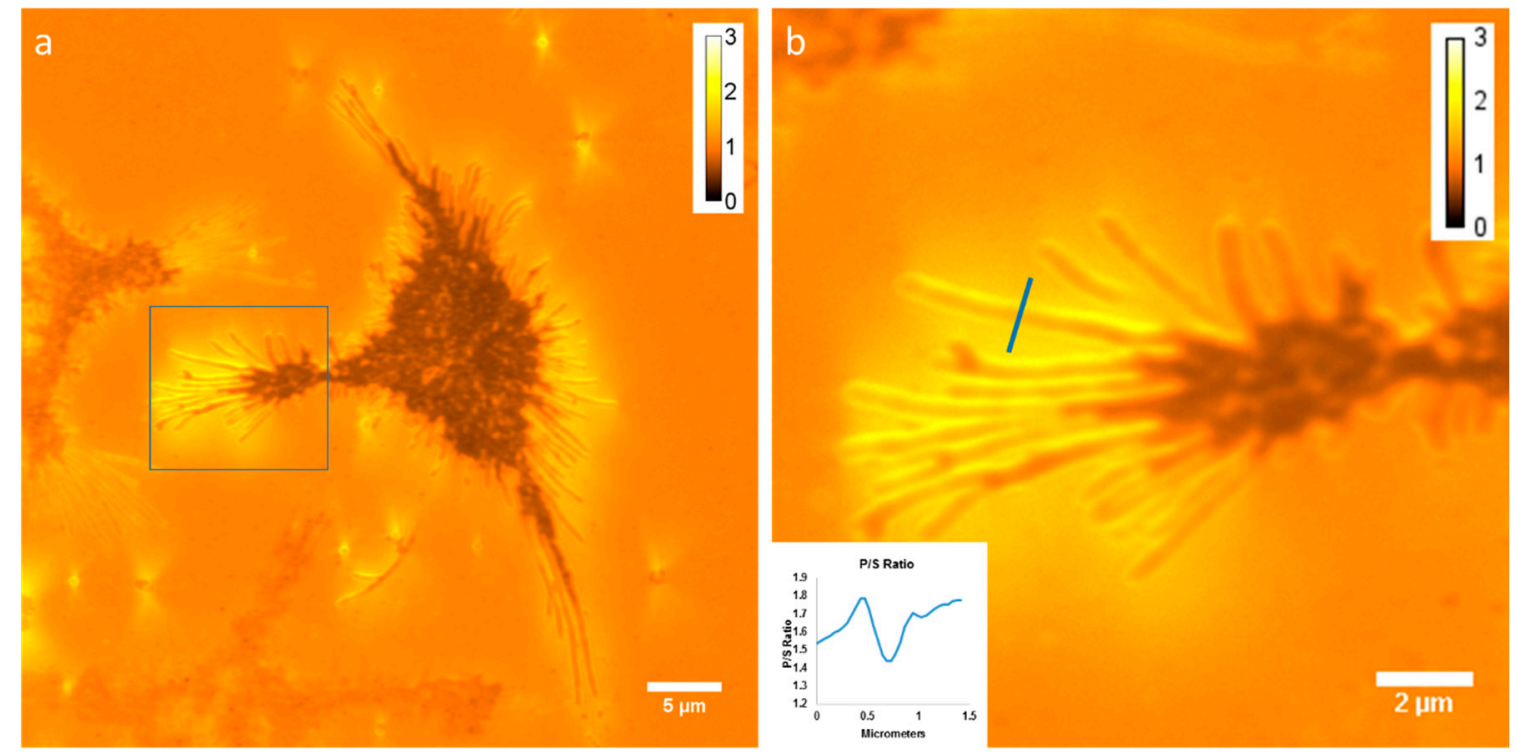

Figure 3. Imaging membrane curvature with DiI- $\mathrm{C}_{16}$ in RBL-2H3 cells grown on a coverslip acquired with the Zyla 4.2+ sCMOS camera. (a) Average of $40 \mathrm{P} / \mathrm{S}$ ratio images. (b) Zoom of the region indicated in a. The inset shows a plot of the $\mathrm{P} / \mathrm{S}$ ratio along the indicated line (from top to bottom of the line).

\subsection{Formation of a FceRI-Centric Synapse on A Supported Lipid Bilayer}

We next imaged RBL-2H3 cells that had been labeled overnight with DyLight488-IgE as they came into contact with a supported lipid bilayer containing 25\% DNP-CAP-PE. As described above, the IgE-488 is bound to cell surface IgE receptors (FceRI), and also to DNP-CAP-PE lipids in the bilayer. After 10-15 min, we observed a wide variety of FceRI-centric synapses in the form of dynamic patches of labeled IgE receptor. This is shown in Figure 4, a gallery of images with various sizes and shapes of IgE receptor patches.

We tested the fluidity of the supported lipid bilayer using a fluorescence recovery after photobleaching (FRAP) method. To do this we labeled the bilayer with a $1 \%$ solution of a BODIPY-conjugated lipid (Thermo Fisher Scientific, D3803), and performed a FRAP experiment using a SP5 confocal microscope (Leica) with warmed objective to $37^{\circ} \mathrm{C}$ using an objective heater (Bioptechs). Fitting of the fluorescence recovery to a diffusion model yielded a diffusion coefficient of $1.6 \mu \mathrm{m}^{2} / \mathrm{sec}$. Widefield observations of the BODIPY-labeled bilayer showed that the bilayer was uniform and intact throughout the coverslip surface. 

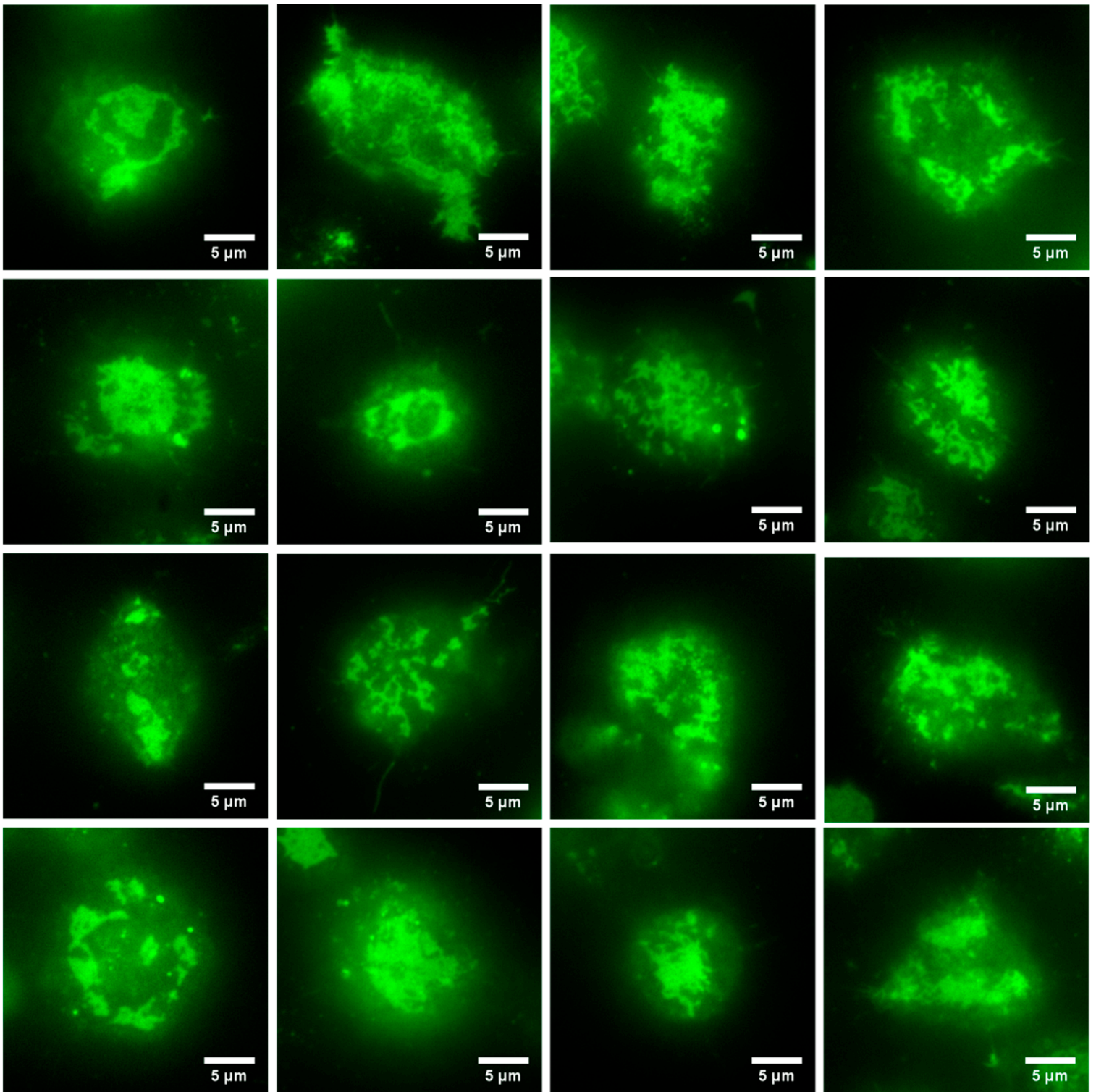

Figure 4. Gallery of images of RBL-2H3 cells labeled overnight with IgE-488 in contact with a supported lipid bilayer containing a lipid derivatized with the IgE ligand DNP. After 10-15 min of contact at $37^{\circ} \mathrm{C}$, we observed a wide variety of patches of IgE-488 labeled FceRI. Images were acquired with the Zyla $4.2+$ sCMOS camera.

\subsection{Imaging of IgE-488 Labeled FceRI with Simultaneous Imaging of Membrane Curvature}

We next imaged RBL-2H3 cells that had been labeled overnight with IgE-488 and were in contact with a supported lipid bilayer containing a lipid derivatized with the IgE ligand DNP, but in this case the cell membrane was also labeled with DiI- $C_{16}$. This experiment is shown in Figure 5 . We observed in many cases that 'holes' in the FceRI patch are evident (for example in Figure 5i), but that these holes are not devoid of cell membrane (Figure 5j). We further analyzed the images by segmenting the image so as to create masks (see Supplemental Figure S1) corresponding to regions containing IgE-bound FceRI (+IgE) or lacking IgE-bound FceRI (-IgE), then plotted normalized histograms of the number of pixels with particular $\mathrm{P} / \mathrm{S}$ ratios in $+\mathrm{IgE}$ and $-\mathrm{IgE}$ regions (Figure 5d,h,l). Membrane regions containing IgE-bound FceRI consistently had lower P/S ratios than those regions lacking the receptor, though this varied considerably from cell to cell. For each cell shown in Figure 5 (and three additional cells, data not shown), a two-sample Kolmogorov-Smirnov test was performed using the statistics toolbox within 
MATLAB. For all cells, the test rejected the null hypothesis that $\mathrm{P} / \mathrm{S}$ ratios in $+\operatorname{IgE}$ and $-\operatorname{IgE}$ regions come from populations with the same distribution at the $5 \%$ significance level.
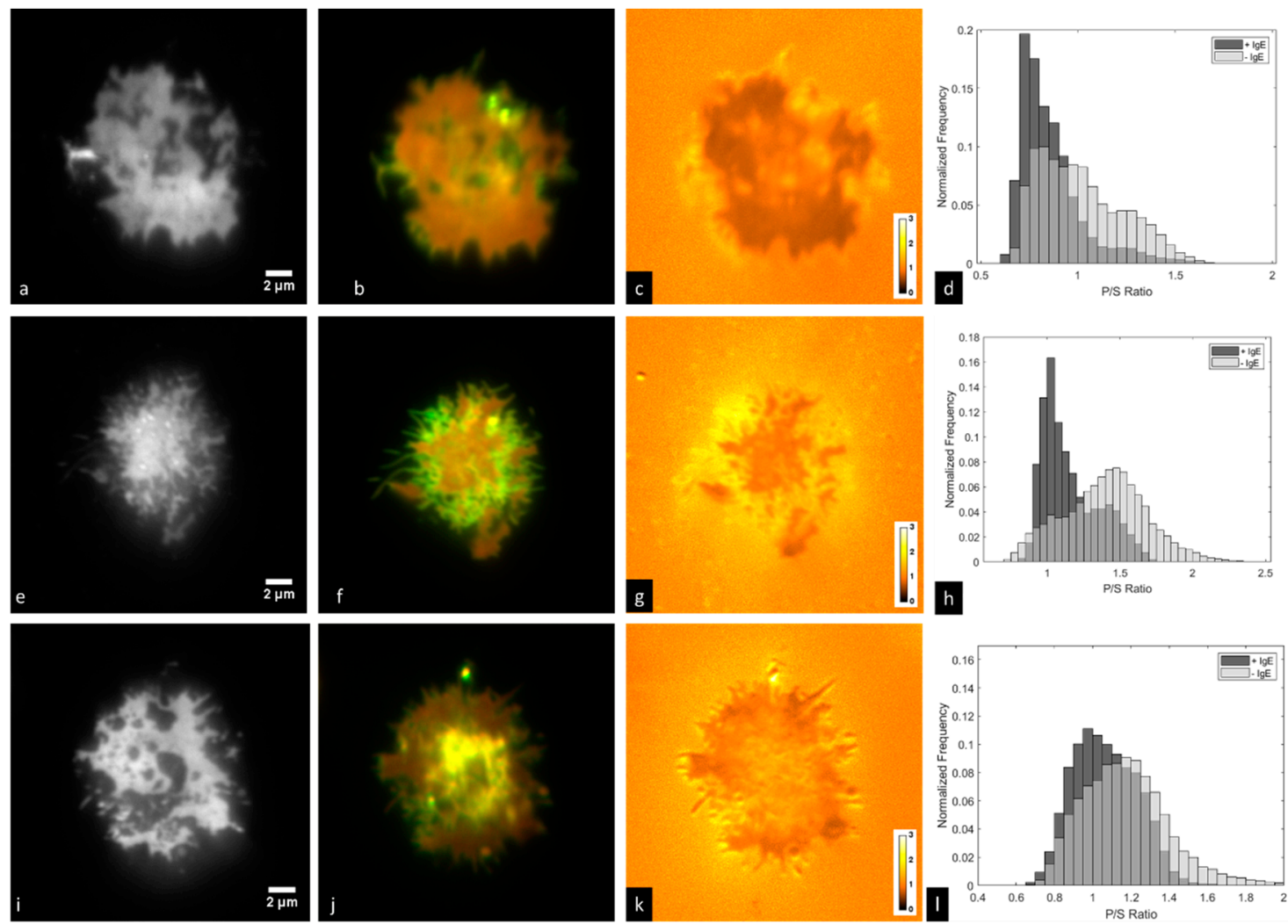

Figure 5. RBL-2H3 cells labeled with IgE-488 and DiI-C 16 in contact with a supported lipid bilayer containing 25\% DNP-CAP-PE. Shown are (a,e,i) IgE-488; $(\mathbf{b}, \mathbf{f}, \mathbf{j})$ two-color overlay of P-polarized excitation and S-polarized excitation signals from DiI- $\mathrm{C}_{16} ;(\mathbf{c}, \mathbf{g}, \mathbf{k}) \mathrm{P} / \mathrm{S}$ ratio images of $\mathrm{DiI}_{-} \mathrm{C}_{16}$ signals; $(\mathbf{d}, \mathbf{h}, \mathbf{l})$ histograms of membrane regions with particular $\mathrm{P} / \mathrm{S}$ ratios for regions positive $(+\mathrm{IgE})$ or negative (-IgE) for IgE-bound FceRI. Images were acquired with the Evolve 512 EMCCD camera and DV2 image splitter.

\subsection{Time-Lapse Imaging of A FceRI-Centric Synapse}

Finally, we imaged RBL-2H3 cells in contact with a supported lipid bilayer over the course of about $4 \mathrm{~min}$. We observed that the IgE- 488 bound FceRI formed a dynamic patch which continually changed shape. Figure 6 shows time-lapse imaging of IgE-488 bound FcERI and a two-color overlay of P-polarized excitation and S-polarized excitation signals from DiI-C ${ }_{16} .10$ time points out of 108 total are shown. Supplementary Video $\mathrm{S} 1$ shows the entire image sequence. 

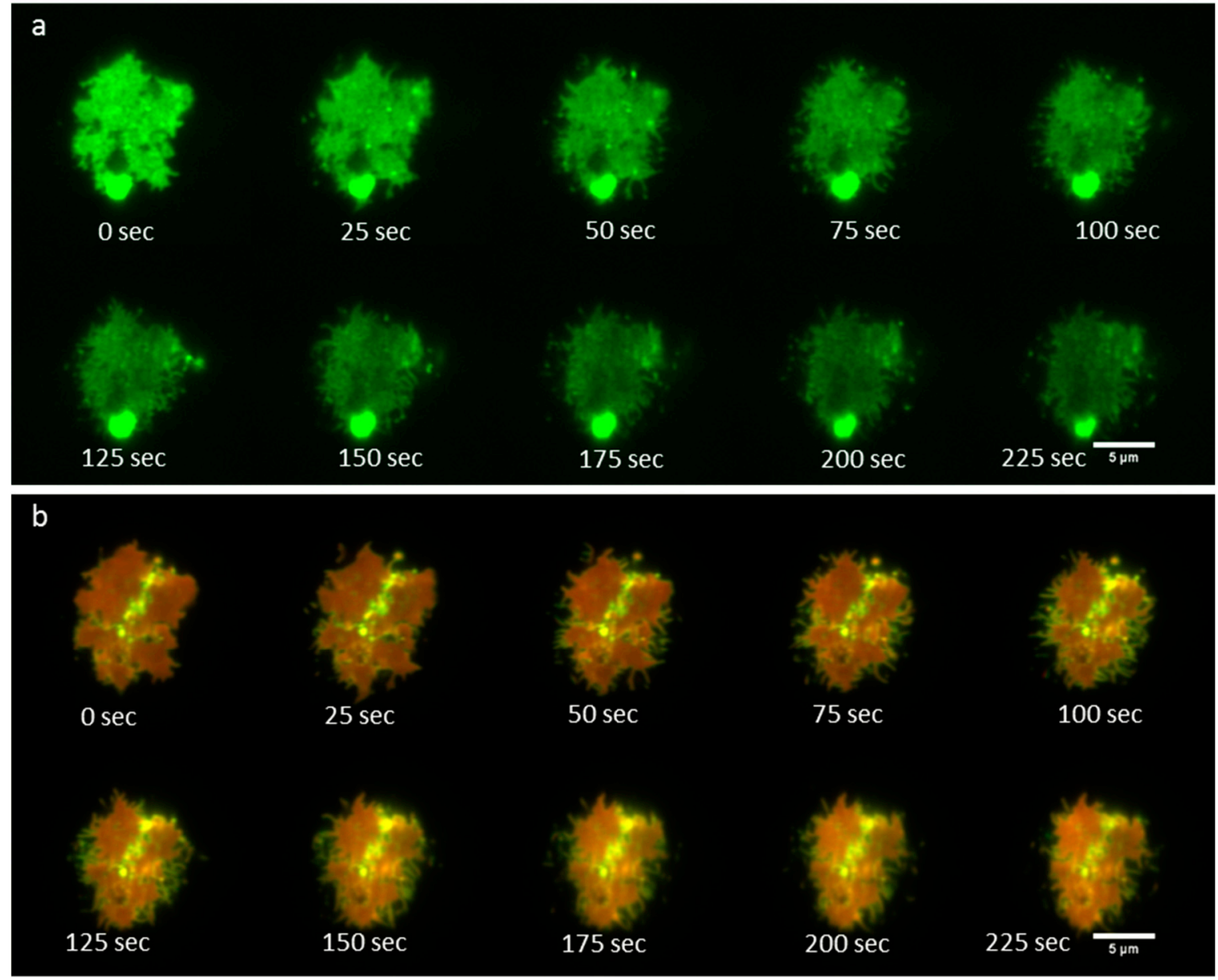

Figure 6. Time-lapse imaging of IgE receptor patch dynamics together with P-TIRF imaging of membrane curvature. (a) IgE-488 bound FceRI; (b) P-S two-color overlay image. Images were acquired with the Zyla 4.2+ sCMOS camera.

\section{Discussion}

The relationship between membrane curvature phenomena and the organization of cell surface receptors responsible for signaling in RBL-2H3 cells has not been well explored. Here we used P-TIRF microscopy to image FceRI-centric synapse formation in live RBL-2H3 cells. We detected membrane curvature using a fluorescent probe that exhibits a specific orientation in the plasma membrane and correlated this with the organization and dynamics of the IgE receptor. Membrane regions containing IgE-bound FceRI consistently had lower $\mathrm{P} / \mathrm{S}$ ratios than those regions lacking the receptor, indicating that regions lacking the receptor are more curved than regions containing the receptor within the cell-substrate contact zone.

In the future, to help reveal the nature of the curvature features we detect, live cell super-resolution microscopy will be valuable. Structured illumination microscopy [32,33] would allow imaging of receptor patch formation with super-resolution, and single molecule localization microscopy methods [34,35] would allow evaluation of nanoscopic membrane features in relation to IgE receptor dynamics.

Supplementary Materials: The following are available online at http://www.mdpi.com/2313-433X/5/7/63/s1, Video S1: Movie of IgE receptor patch dynamics together with P-TIRF imaging of membrane curvature. Figure S1: Image masks used to create normalized histograms of the number of pixels with particular $\mathrm{P} / \mathrm{S}$ ratios in $+\mathrm{IgE}$ and -IgE regions shown in Figure 5. Figure S2. Image showing composite of IgE signal (red) and P-S ratio (green) from (a) Figure $5 b, i, k)$ Figure $5 a, c$ of the main text. 
Author Contributions: Conceptualization, K.S.; formal analysis, R.M., K.S. and G.M.H.; funding acquisition, K.S. and G.M.H.; investigation, R.M., J.B., M.B. and G.M.H.; methodology, K.S. and G.M.H.; supervision, K.S. and G.M.H.; visualization, R.M. and G.M.H.; writing—original draft, K.S. and G.M.H.; writing—review and editing, K.S. and G.M.H.

Funding: Research reported in this publication was supported by the National Institute of General Medical Sciences of the National Institutes of Health under award number 1R15GM128166-01 and by the National Science Foundation under Grant Number 1727033. This work was also supported by the University of Colorado, Colorado Springs (UCCS) center for the University of Colorado BioFrontiers Institute and by the UCCS Committee for Research and Creative Work grant.

Conflicts of Interest: The authors declare no conflict of interest. The funders had no role in the design of the study; in the collection, analyses, or interpretation of data; in the writing of the manuscript, or in the decision to publish the results. Any opinions, findings, and conclusions or recommendations expressed in this material are those of the authors and do not necessarily reflect the views of the National Science Foundation.

\section{References}

1. Monks, C.R.F.; Freiberg, B.A.; Kupfer, H.; Sciaky, N.; Kupfer, A. Three-dimensional segregation of supramolecular activation clusters in T cells. Nature 1998, 395, 82-86. [CrossRef] [PubMed]

2. Kaizuka, Y.; Douglass, A.D.; Varma, R.; Dustin, M.L.; Vale, R.D. Mechanisms for segregating T cell receptor and adhesion molecules during immunological synapse formation in Jurkat T cells. Proc. Natl. Acad. Sci. USA 2007, 104, 20296-20301. [CrossRef] [PubMed]

3. Carroll-Portillo, A.; Cannon, J.L.; Te Riet, J.; Holmes, A.; Kawakami, Y.; Kawakami, T.; Cambi, A.; Lidke, D.S. Mast cells and dendritic cells form synapses that facilitate antigen transfer for T cell activation. J. Cell Biol. 2015, 210, 851-864. [CrossRef] [PubMed]

4. Mantri, C.K.; John, A.L., St. Immune synapses between mast cells and $\gamma \delta \mathrm{T}$ cells limit viral infection. J. Clin. Investig. 2019, 129, 1094-1108. [CrossRef] [PubMed]

5. Carroll-Portillo, A.; Spendier, K.; Pfeiffer, J.; Griffiths, G.; Li, H.; Lidke, K.A.; Oliver, J.M.; Lidke, D.S.; Thomas, J.L.; Wilson, B.S.; et al. Formation of a mast cell synapse: Fc epsilon RI membrane dynamics upon binding mobile or immobilized ligands on surfaces. J. Immunol. 2010, 184, 1328-1338. [CrossRef] [PubMed]

6. Spendier, K.; Lidke, K.A.; Lidke, D.S.; Thomas, J.L. Single-particle tracking of immunoglobulin E receptors (FceRI) in micron-sized clusters and receptor patches. FEBS Lett. 2012, 586, 416-421. [CrossRef] [PubMed]

7. Spendier, K.; Carroll-Portillo, A.; Lidke, K.A.; Wilson, B.S.; Timlin, J.A.; Thomas, J.L. Distribution and dynamics of rat basophilic leukemia immunoglobulin E receptors (FcepsilonRI) on planar ligand-presenting surfaces. Biophys. J. 2010, 99, 388-397. [CrossRef]

8. Song, J.; Hagen, G.M.; Roess, D.A.; Pecht, I.; Barisas, B.G. The mast cell function-associated antigen and its interactions with the type I FcE receptor. Biochemistry 2002, 41, 881-889. [CrossRef]

9. Balakrishnan, K.; Hsu, F.J.; Cooper, A.D.; McConnell, H.M. Lipid hapten containing membrane targets can trigger specific immunoglobulin E-dependent degranulation of rat basophil leukemia cells. J. Biol. Chem. 1982, 257, 6427-6433.

10. Thomas, J.L.; Feder, T.J.; Webb, W.W. Effects of protein concentration on IgE receptor mobility in rat basophilic leukemia cell plasma membranes. Biophys. J. 1992, 61, 1402-1412. [CrossRef]

11. Weis, R.M.; Balakrishnan, K.; Smith, B.A.; Mcconnell, H.M.; Smithy, B.A.; Mcconnell, H.M. Stimulation of fluorescence in a small contact region between rat basophil leukemia cells and planar lipid membrane targets by coherent evanescent radiation. J. Biol. Chem. 1982, 257, 6440-6445. [PubMed]

12. Pfeiffer, J.R.; Seagrave, J.C.; Davis, B.H.; Deanin, G.G.; Oliver, J.M. Membrane and cytoskeletal changes associated with IgE-mediated serotonin release from rat basophilic leukemia cells. J. Cell Biol. 1985, 101, 2145-2155. [CrossRef] [PubMed]

13. Bassereau, P.; Jin, R.; Baumgart, T.; Deserno, M.; Dimova, R.; Frolov, V.A.; Bashkirov, P.V.; Grubmüller, H.; Jahn, R.; Risselada, H.J.; et al. The 2018 biomembrane curvature and remodeling roadmap. J. Phys. D Appl. Phys. 2018, 51, 343001. [CrossRef] [PubMed]

14. Spendier, K. N-terminal amphipathic helix of Amphiphysin can change the spatial distribution of immunoglobulin E receptors (FceRI) in the RBL-2H3 mast cell synapse. Results Immunol. 2016, 6, 1-4. [CrossRef] [PubMed]

15. Schmick, M.; Bastiaens, P.I.H. The interdependence of membrane shape and cellular signal processing. Cell 2014, 156, 1132-1138. [CrossRef] [PubMed] 
16. Axelrod, D. Carbocyanine dye orientation in red cell membrane studied by microscopic fluorescence polarization. Biophys. J. 1979, 26, 557-573. [CrossRef]

17. Sund, S.E.; Swanson, J.A.; Axelrod, D. Cell membrane orientation visualized by polarized total internal reflection fluorescence. Biophys. J. 1999, 77, 2266-2283. [CrossRef]

18. Axelrod, D. Chapter 7: Total internal reflection fluorescence microscopy. Methods Cell Biol. 2008, 89, $169-221$. [PubMed]

19. Passmore, D.R.; Rao, T.C.; Peleman, A.R.; Anantharam, A. Imaging plasma membrane deformations with pTIRFM. J. Vis. Exp. 2014, 86, e51334. [CrossRef]

20. Anantharam, A.; Axelrod, D.; Holz, R.W. Real-time imaging of plasma membrane deformations reveals pre-fusion membrane curvature changes and a role for dynamin in the regulation of fusion pore expansion. J. Neurochem. 2012, 122, 661-671. [CrossRef]

21. Anantharam, A.; Axelrod, D.; Holz, R.W. Polarized TIRFM reveals changes in plasma membrane topology before and during granule fusion. Cell. Mol. Neurobiol. 2010, 30, 1343-1349. [CrossRef] [PubMed]

22. Anantharam, A.; Onoa, B.; Edwards, R.H.; Holz, R.W.; Axelrod, D. Localized topological changes of the plasma membrane upon exocytosis visualized by polarized TIRFM. J. Cell Biol. 2010, 188, 415-428. [CrossRef] [PubMed]

23. Johnson, D.S.; Toledo-Crow, R.; Mattheyses, A.L.; Simon, S.M. Polarization-controlled TIRFM with focal drift and spatial field intensity correction. Biophys. J. 2014, 106, 1008-1019. [CrossRef] [PubMed]

24. Oreopoulos, J.; Yip, C.M. Probing membrane order and topography in supported lipid bilayers by combined polarized total internal reflection fluorescence-atomic force microscopy. Biophys. J. 2009, 96, 1970-1984. [CrossRef] [PubMed]

25. Ramirez, D.M.C.; Jakubek, Z.J.; Lu, Z.; Ogilvie, W.W.; Johnston, L.J. Changes in order parameters associated with ceramide-mediated membrane reorganization measured using pTIRFM. Langmuir 2013, 29, 15907-15918. [CrossRef] [PubMed]

26. Werner, J.H.; Montaño, G.A.; Garcia, A.L.; Zurek, N.A.; Akhadov, E.A.; Lopez, G.P.; Shreve, A.P. Formation and Dynamics of Supported Phospholipid Membranes on a Periodic Nanotextured Substrate. Langmuir 2009, 25, 2986-2993. [CrossRef] [PubMed]

27. Edelstein, A.; Amodaj, N.; Hoover, K.; Vale, R.; Stuurman, N. Computer control of microscopes using $\mu$ Manager. Curr. Protoc. Mol. Biol. 2010, 92, 14.20.1-14.20.17.

28. Edelstein, A.D.; Tsuchida, M.A.; Amodaj, N.; Pinkard, H.; Vale, R.D.; Stuurman, N. Advanced methods of microscope control using $\mu$ Manager software. J. Biol. Methods 2014. [CrossRef]

29. Friedman, L.J.; Chung, J.; Gelles, J. Viewing dynamic assembly of molecular complexes by multi-wavelength single-molecule fluorescence. Biophys. J. 2006, 91, 1023-1031. [CrossRef]

30. Ellefsen, K.L.; Dynes, J.L.; Parker, I. Spinning-spot shadowless TIRF microscopy. PLoS ONE 2015, 10, e0136055. [CrossRef]

31. Hendriks, C.L.L.; van Vliet, L.J.; Rieger, B.; van Kempen, G.M.P.; van Ginkel, M. Dipimage: A Scientific Image Processing Toolbox for MATLAB; Quantitative Imaging Group, Faculty of Applied Sciences, Delft University of Technology: Delft, The Netherlands, 1999.

32. Pospíšil, J.; Lukeš, T.; Bendesky, J.; Fliegel, K.; Spendier, K.; Hagen, G.M. Imaging tissues and cells beyond the diffraction limit with structured illumination microscopy and Bayesian image reconstruction. Gigascience 2019, 8, giy126. [CrossRef] [PubMed]

33. Gustafsson, M.G.L. Surpassing the lateral resolution limit by a factor of two using structured illumination microscopy. J. Microsc. 2000, 198, 82-87. [CrossRef] [PubMed]

34. Ovesný, M.; Kř́žek, P.; Borkovec, J.; Švindrych, Z.; Hagen, G.M. ThunderSTORM: A comprehensive ImageJ plug-in for PALM and STORM data analysis and super-resolution imaging. Bioinformatics 2014, 30, 2389-2390. [CrossRef] [PubMed]

35. Rust, M.J.; Bates, M.; Zhuang, X. Sub-diffraction-limit imaging by stochastic optical reconstruction microscopy (STORM). Nat. Methods 2006, 3, 793-795. [CrossRef] [PubMed]

(C) 2019 by the authors. Licensee MDPI, Basel, Switzerland. This article is an open access article distributed under the terms and conditions of the Creative Commons Attribution (CC BY) license (http://creativecommons.org/licenses/by/4.0/). 